\title{
Encouraging Gameful Experience in Digital Game-Based Learning: A Double- Mediation Model of Perceived Instructional Support, Group Engagement, and Flow
}

\author{
Mona Höyng \\ University of Duisburg-Essen, Germany \\ mona.hoeyng@uni-due.de
}

\begin{abstract}
In the current digitalization era, digital game-based learning (DGBL) is used in education to engage and motivate students. Gameful experience $(G E)$ is a crucial precondition to determine the effectiveness of these games. However, previous research focused solely on the effects of games on inter alia student engagement, and empirical research regarding $G E$ is lacking. This study investigates the factors that encourage students' GE. Grounded in the theory of experience, a double-mediation model is developed that considers the direct relationship between instructional support and students' GE and examines how group engagement and flow mediate this relationship. Data from 336 students participating in a team-based business simulation game revealed that group engagement and flow sequentially double-mediated the positive relationship between instructional support and GE. Thus, to encourage students' GE, educators and education institutions should provide appropriate instructional support that promotes group engagement as well as flow among students.
\end{abstract}

\section{Introduction}

In the current digitalization era, digital game-based learning (DGBL) has rapidly become a new trend in education $[1,2,3]$. Because most students today are considered digital natives, as they grew up with digital technologies, they have new requirements as learners $[4,5]$.

The use of games in education can engage and motivate students. Prior research provided evidence that using games in education can be more effective than conventional instruction, such as lectures $[6,7]$. Specifically, with the introduction of digital business simulation games in higher education, students access educational content in a more enjoyable and interactive way [8]. Simulated scenarios help students acquire management skills and competencies, such as problem-solving and decision-making, that are required in the business world [8]. In contrast to organizational processes in real world, business simulation games represent risk-free environments that enable students to learn by doing and to learn from their failures [9].

While some studies emphasized the advantages of DGBL and business simulation games [3, 9], others showed that simulation games were no more motivating than conventional instruction [6]. A necessary precondition to determine the effectiveness of these games and the students' overall value creation is the gameful experience (GE) these games encourage $[10,11,12]$.

However, a recent literature review on DGBL found a lack of empirical research regarding the factors that encourage students' GE when playing business simulation games. Thus, the primary aim of the current study is to empirically investigate the factors that encourage students' GE.

Based on the theory of experience $[13,14]$ and prior research, a double-mediation model is developed that empirically investigates the direct relationship between perceived instructional support and students' GE and examines how group engagement and flow mediate this relationship (see Figure 1). The results of this study provide researchers and educators with insights into improving students' GE. Thus, business simulation games may be implemented more effectively to enhance inter alia student motivation and learning.

\section{Theoretical background and hypotheses development}

The use of business simulation games in higher education and students' GE are investigated in the context of DGBL, serious games, or gamification of learning $[6,7,8$, 9]. DGBL describes the use of digital games, simulations, or other gamified learning activities to fulfill one or more learning objectives, such as encouraging students' GE [3, 15]. Thereby, DGBL can be referred to a specific instructional method that encompasses serious games and gamification of learning with the goal of affecting learning directly $[7,16,17]$.

GE in general refers to the positive emotional involvement that results from playing a game or using a gamified 
application. GE is considered the primary goal of games and gamified applications [18]. In this regard, previous research confirmed that GE is a necessary precondition for various desired outcomes, such as student engagement $[17,25,27]$ and subsequently the effectiveness of games, such as the business simulation game examined in this study. It was found that, if GE is lacking, the goals of gamification, such as increasing user motivation, will remain unachieved [15].

Regarding the conceptualization, Eppmann et al. [18] developed the GAMEX scale, which includes the following six dimensions of GE. Enjoyment and absence of negative affect concern users' positive emotions and involvement. Absorption reflects intense cognitive engagement and a feeling of disconnection from the actual environment [2]. Creative thinking indicates that a game has inspired users' imaginations and sense of exploration. Activation describes the stimulation of emotions, thoughts, and actions. Finally, dominance assesses users' feeling of control while playing [2].

In contrast to the GAMEX scale, Högberg et al. [10] identified seven dimensions of GE - accomplishment, challenge, competition, guided, immersion, playfulness, and social - in their GAMEFULQUEST questionnaire [10]. Contrary to GAMEX, GAMEFULQUEST does not consider the negative aspects of playing games as a dimension of GE, but as an outcome of GE [10]. Several studies have emphasized the importance of the absence of these negative aspects when considering GE $[19,20]$. Further, in the educational context, negative affect has been found to negatively influence student learning [21]. Thus, the GAMEX scale is of particular importance to this study. Although this scale has been validated in various contexts, such as marketing [18] and nursing [19, 22], it has not been applied to or validated for the use in educational contexts, such as DGBL. To address this research gap, the GAMEX scale is used in this study to empirically investigate students' GE.

The importance of investigating GE in DGBL is supported by the theory of experience developed by Dewey $[13,14]$. According to this theory, students learn through continuous experience $[13,23]$. The theory of experience seems particularly suitable for investigating GE in business simulation games in higher education, as the theory has been applied to analyze student learning in education in general [13]. However, no study has yet empirically applied this theory in the context of business simulation games. Following the theoretical assumptions of Dewey [13], GE is argued to be a crucial factor influencing student learning, based on the principles of continuity and interaction [13, 23]. On the basis of continuity, students' previous and current experiences in gaming should affect their future experiences. In addition, students reflect on and evaluate their experiences and actions as well as those of their classmates, paving the way for growth and new experiences [13, 24, 25]. In contrast, mis-educative experiences involve negative emotional, physical, and social aspects that inhibit new experiences and growth [14, 24]. Thus, understanding factors that encourage GE is essential for future experiences in gaming. Regarding the principle of interaction, students' exchanges within physical or social game settings are of particular importance in the current study since communal learning expands students' learning experiences $[13,23]$. This study considers instructional support, in terms of the interaction between instructors and students, an important factor in promoting students' GE and in determining the effectiveness of business simulation games and future GE [26, 27, 28]. The mediating effect of interpersonal and individual factors in terms of group engagement [20, 27, 29] and flow [30, 31, 32] are of particular importance and explained in detail below.

The hypotheses derived in the following section are differentiated into the six dimensions of GE, based on the GAMEX scale.

\subsection{Perceived instructional support}

As business simulation games require learners to understanding complex relationships, they may be ineffective when used as stand-alone tools [27]. Therefore, in line with theory of gamified learning, providing instructional support in terms of instructional content in games, such as narratives, promotes desired learning-related behavior or attitudes [7]. In addition to instructional content and support strategies, such as online help or cues, support from instructors was identified as a central factor in the context of DGBL [27, 33]. While game play is typically voluntary, instructional support is typically mandatory help provided by an instructor, with the aim of achieving certain learning outcomes [27, 34, 35]. Instructional support may involve giving feedback, facilitating users to focus on the key aspects of the game [26, 36], or being supportive [37].

According to the theory of experience [13], instructors play a key role in bolstering students' learning experiences, which includes GE $[37,38]$. More precisely, instructors who are perceived as supportive, in terms of providing feedback and being knowledgeable and responsive, encourage positive learning experiences [37]. In contrast, students who perceive a lack of support from their instructors endure negative learning experiences [37]. Hence, it is argued that perceived instructional support fosters positive emotional experiences with the game, described by GE in terms of enjoyment. Further, perceived instructional support is not related to negative emotions, implying absence of negative affect. Proserpio and Magni [39] stated that instructional support prevents students from becoming distracted, enabling them to pay more attention to the task. While a lack of support increases the difficulties and frustrations related to the game, providing 
instructional support encourages users to focus on the key aspects of the game [26, 36], suggesting positive GE in terms of absorption. In addition, students' GE in terms of creative thinking is encouraged through the use of games [40] and is expected to be increased by instructional support [41]. Moreover, it is assumed that the perception of instructional support fosters students' stimulation in games [28]. Therefore, students' level of activity is promoted [18, 42], fostering their GE in terms of activation. Finally, instructional support may enable GE in terms of dominance. According to ter Vrugte and Jong [32], this is achieved by providing students with control while playing games. Further, instructors may enable students to structure their learning and select relevant information on their own [32] to enhance their level of dominance [2, 33].

In contrast, some researchers suggested that instructional support restricts users' freedom to discover the game, potentially diminishing their motivation and sense of fun $[43,44]$. However, most teachers need to offer some advice and support to ensure that learning is actually taking place [45] and to develop self-directed learners [27]. Thus, it is emphasized that instructors should guide but not interfere with the learning process [14]. Adequate instructional support must be provided to promote GE in terms of all its dimensions, implying that these games become effective learning media [6]. Consequently, the following is hypothesized:

H1: Perceived instructional support is positively related to students' GE in terms of enjoyment, absence of negative affect, absorption, creative thinking, activation, and dominance.

\subsection{Mediating role of group engagement}

As this study focuses on a team-based business simulation game, the use of games is expected to encourage group collaboration and deepen students' learning experiences in terms of GE $[29,46]$. Therefore, group engagement is considered an interpersonal factor in this study, characterized as a sense of group identity, in which group members share and participate in similar experiences and understand each other [47].

In this study, group engagement is expected to mediate the relationship between perceived instructional support and GE. This is because instructors are able to support and promote students' group engagement within the game [20, 48], thus enhancing GE [27]. While instructors play a key role in encouraging group engagement [20, 48], it is argued - in line with theory of experience $[13,14]$ - that group engagement is crucial to develop GE. In the context of DGBL, group engagement fosters positive learning experiences in terms of enjoyment and absence of negative affect [46, 49]. However, group engagement may distract users from the game [50], thereby affecting GE in terms of absorption. Moreover, past research confirmed that group engagement stimulates creative thinking in online learning environments [51], such as DGBL. Group engagement in terms of group work was found to enhance students' creativity [52] and subsequently may increase GE in terms of creative thinking. Likewise, prior research provided evidence that group engagement in a team-based game fosters stimulation [53], thus affecting GE in terms of activation. Finally, group engagement encourages students to structure their learning processes and master challenges on their own $[1,37]$. Therefore, students feel dominant and in control while playing the game [2]. Thus, their $\mathrm{GE}$ in terms of dominance is encouraged. Based on the preceding arguments, the following is posited:

H2: Group engagement partially mediates the relationship between perceived instructional support and students' $G E$ in terms of enjoyment, absence of negative affect, absorption, creative thinking, activation, and dominance.

\subsection{Mediating role of flow}

Flow has been widely identified as a predisposing factor concerning the effectiveness of games [31]. Therefore, it is considered an individual factor in this study. Flow is characterized as a highly concentrated state of mind, in which individuals completely disregard their environment and irrelevant perceptions. Flow is often experienced in gaming [31, 54, 55].

Due to similarities between flow and the GE dimension of absorption, researchers have suggested that flow is a part of GE [56]. These two constructs can be distinguished by considering the type of affect experienced in games [57]. In particular, the negative aspects of gaming, such as anxiety, contradict the understanding of flow, but they are included in the construct of GE [57]. Further, scholars argue that the experience of flow is more extreme than GE in terms of absorption [18, 57]. Absorption describes total engagement in the present experience; flow is related to a game engagement factor that reflects a specific degree of participation antecedent to GE $[18,57]$. Thus, the two constructs investigated as distinct in this study, in which flow is considered an antecedent of GE.

In this study, flow is expected to mediate the relationship between perceived instructional support and students' GE. This assumption is derived from research arguing that instruction in games significantly impacts students' sense of flow [31, 58]. Particularly, Shin [59] postulated that instructional support encourages students' flow. In turn, flow was found to relate to positive subjective experience [58], such as GE. Several studies in the context of DGBL emphasized that games encourage flow, thus positively affecting students' enjoyment and absorption in learning $[60,61]$. Subsequently, students' GE in terms of enjoyment, absence of negative affect and absorption is assumed to be promoted by games in DGBL that encourage 
flow [30]. Further, researchers have indicated that flow enhances creative thinking [30], resulting in higher GE in terms of creative thinking among students. As flow describes an individual who has become "one with the activity," high levels of arousal are expected [55, 57]. This may result in higher GE in terms of activation. Finally, students experiencing flow are expected to feel in charge and dominant in the game, implying higher GE in terms of dominance [2, 33]. In contrast, ter Vrugte and de Jong [32] emphasized that support may also inhibit flow, and students' GE as a consequence. As the feeling of flow usually provides no room for reflection, which is triggered by providing support, it is argued that support disrupts students' sense of flow and their subsequent enjoyment while playing games [32, 35]. Nevertheless, support is necessary for individuals to select relevant information and to benefit from learning [35]. Thus, support must be provided - but very carefully - to encourage students' flow [32, 35] and GE. Based on the preceding arguments, the following is posited:

H3: Flow partially mediates the relationship between perceived instructional support and students' $G E$ in terms of enjoyment, absence of negative affect, absorption, creative thinking, activation, and dominance.

\subsection{Double-mediation effect of group en- gagement and flow}

Further, it is hypothesized in the current paper that interpersonal and individual factors (i.e., group engagement and flow) sequentially double-mediate the relationship between perceived instructional support and students' GE. As elucidated above, perceived instructional support was found to promote group engagement [62]. In turn, group engagement intensifies students' flow. This assumption derives from prior research stating that students' group engagement further encourages flow [63]. Conversely, interactions with group members may inhibit flow by bringing users out of the fantasy world and into the real world [64]. Although some studies highlight the disruptive effects of group engagement on flow, group engagement remains a relevant factor in our hypothesized double-mediation model [64]. Group engagement is expected to be a necessary prerequisite in intensifying students' flow and GE in terms of all its dimensions $[30,57,58,60]$. Thus, the following is to posit:

H4: Group engagement and flow sequentially double-mediate the relationship between perceived instructional support and students' $G E$ in terms of enjoyment, absence of negative affect, absorption, creative thinking, activation, and dominance.

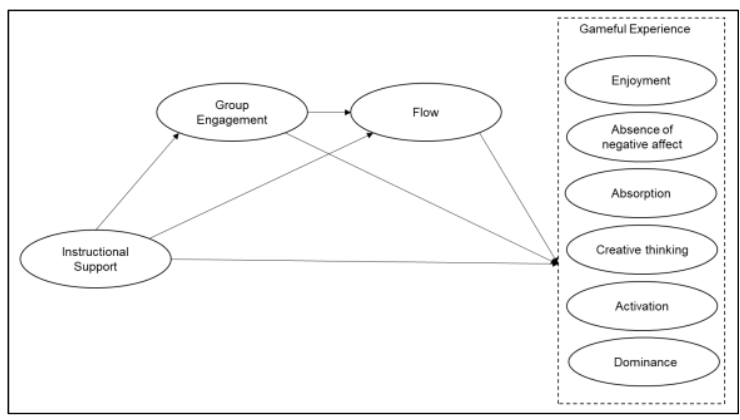

Figure 1: Proposed research model

\section{Method}

\subsection{Data collection and Participants}

For data collection, the headquarters of the company that offers the business simulation game as well as 36 institutions using the game were contacted by email. Overall, data from 346 students were collected in an online survey. For data cleansing, the datasets of students who did not agree to data protection $(n=7)$ and of those who had previously participated in the survey $(n=3)$ were eliminated. As the sample varied in terms of experience and intensity of online gaming, sample bias is not expected to impact the results. Subsequently, 336 datasets remained (final response rate: $56.95 \%$ ), forming the basis for the following analyses. Table 1 provides a detailed overview of the study's respondents.

\subsection{Procedure}

The business simulation game investigated in this study is a computer-based management and strategy game. This game was conducted at two German universities over one week (Monday through Friday), ending with an online survey on the last day. The game can be described by means of continuity and interaction. Regarding the dimension of continuity, the game was divided into six time periods and an additional test period on the first day of the game. In each period, participants, acting as board members of an industrial company, had to make operative business decisions in all departments of the company, such as sales and accounting (e.g., regarding the development, production, and sale of a specific product) with the aim of realizing higher profits than their competitors. After each decision-making period, the participants' decisions were analyzed and evaluated. By doing so, previous decisions determined present and future decisions. By means of interaction, up to six students worked together to form a board that competed against other groups. Thereby, all decisions of a board were made at team level. Further, an instructor explained the business simulation game in detail. Interacting with an instructor and group members 
encouraged students to explain the results theoretically and, if necessary, to rethink the groups' strategy.

In line with Hernández-Lara et al. [20], the business simulation game aims to increase students' understanding of the complex business environment and of decisionmaking in business. Further, students should practice teamwork and problem-solving as well as get insights into management disciplines [20]. Last, students were able to apply the theoretical knowledge they had acquired in their classes to practice [20].

\section{Table 1: Detailed information about respondents}

\begin{tabular}{|c|c|c|}
\hline Characteristics & $\begin{array}{c}\text { Number } \\
(\mathrm{n})\end{array}$ & $\begin{array}{c}\text { Percentage } \\
(\%)\end{array}$ \\
\hline \multicolumn{3}{|l|}{ Sex } \\
\hline Female & 1602 & 48.2 \\
\hline Male & 174 & 51.8 \\
\hline \multicolumn{3}{|l|}{ Age (in years) } \\
\hline $20-24$ & 277 & 82.44 \\
\hline $25-29$ & 53 & 15.8 \\
\hline $30-38$ & 6 & 1.8 \\
\hline \multicolumn{3}{|l|}{ Engagement } \\
\hline$<5$ hours & 123 & 37.61 \\
\hline 5-10 hours & 82 & 24.40 \\
\hline $11-20$ hours & 54 & 16.07 \\
\hline 21-30 hours & 31 & 9.23 \\
\hline$>31$ hours & 46 & 13.69 \\
\hline \multicolumn{3}{|c|}{ University affiliation } \\
\hline University 1 & 314 & 93.5 \\
\hline University 2 & 22 & 6.5 \\
\hline \multicolumn{3}{|l|}{ Year of study } \\
\hline $1-4$ & 44 & 13.1 \\
\hline $5-9$ & 277 & 82.4 \\
\hline $10-16$ & 15 & 4.5 \\
\hline \multicolumn{3}{|l|}{ GPA } \\
\hline $1.2-1.9$ & 58 & 17.3 \\
\hline $2.0-2.4$ & 107 & 31.8 \\
\hline $2.5-2.9$ & 135 & 40.2 \\
\hline $3.0-3.4$ & 36 & 10.7 \\
\hline \multicolumn{3}{|c|}{$\begin{array}{l}\text { Language difficulties } \\
\text { (group) }\end{array}$} \\
\hline Yes & 24 & 7.1 \\
\hline No & 312 & 92.9 \\
\hline \multicolumn{3}{|c|}{$\begin{array}{l}\text { Language difficulties } \\
\text { (individual) }\end{array}$} \\
\hline Yes & 10 & 3.0 \\
\hline No & 326 & 97.0 \\
\hline
\end{tabular}

Note. $N=336$; For GPA: 1 = highest to $6=$ lowest.

\subsection{Measures}

All items were measured on a 5-point Likert scale, from 1 = strongly disagree to $5=$ strongly disagree .

3.3.1. Gameful experience (GE). The German version of the 27-item GAMEX scale, developed by Eppmann et al. [18], was used to assess students' GE. By testing the dimensionality of this construct, the results of a confirmatory factor analysis (CFA) showed a good fit of the sixfactor model compared to the competing models.
However, based on the standardized factor loadings, the dimension activation lacked reliability and validity (standardized factor loadings ranged from .26 to $.56, p<.01$, composite reliability $[\mathrm{CR}]=.56$, average variance extracted $[\mathrm{AVE}]=.26$ ), which is why elimination of this factor was suggested [65]. This was further justified due to content-related considerations (e.g., ambiguous meanings) regarding the items that do not sufficiently relate to the corresponding factor. Thus, activation was omitted from the analyses. Consequently, in the five-factor model $\left(\chi^{2} / d f=2.61\right.$, standardized root mean square residual $[\mathrm{SRMR}]=.07$, root mean-square error of approximation $[\mathrm{RMSEA}]=.07$, comparative fit index $[\mathrm{CFI}]=.94$, Tucker-Lewis index [TLI] = .93), all items loaded statistically significantly on their respective latent factor, and all factors showed very good reliability $(\mathrm{CR}=.77-.93$, AVE $>.50)$.

3.3.2. Perceived instructional support. A four-item scale was used to measure perceived instructional support. In this study, items from the short version measuring perceived supervisor support, developed by Rhoades et al. [66], were adapted to the specific educational context by replacing the supervisor with instructor in every item. A sample item is "My supervisor cares about my opinion," which was adapted to "My instructor cares about my opinion." The CR value for the four-item scale was .80.

3.3.3. Group engagement. To assess group engagement, seven items from the German Group Climate Questionnaire (GCQ-S), originally developed by MacKenzie [67] and translated into German by Tschuschke et al. [68], were used. One item was eliminated due to poor factor loading. The CR value for the six-item scale was .83 .

3.3.4. Flow. Ten items from the German Flow Short scale, developed by Rheinberg et al. [69], were used to measure students' flow intensity. Owing too poor and insignificant factor loadings, two items were eliminated. The CR value for the eight flow items was .82.

3.3.5. Control variables. Students' gender, age, engagement (time required for preparations and follow-up of lectures and seminars), university affiliation, year of study, and GPA were included as control variables in this study. Additionally, students' language difficulties in individual and group work, and the time points of the game (as the game was conducted at three different time points in the two universities) were controlled for in the current study.

\subsection{Data analysis}

Data were analyzed using SPSS 26, AMOS 26, and the PROCESS macro, developed by Hayes [70]. First, the distinction between GE in terms of absorption and flow was assessed empirically using exploratory factor analysis (EFA). Second, CFA was conducted to establish the convergent and discriminant validity of the measurement 
model $[71,72]$. Then, common method variance (CMV) was controlled for, as self-report measures and singlesource data were used [73, 74]. To separately test H1, multiple hierarchical regression analyses were performed. Then, the mediation hypotheses $(\mathrm{H} 2-\mathrm{H} 4)$ were examined in PROCESS using 5,000 bootstrap samples. Bias-corrected confidence intervals (CIs) and the stepwise procedure were thereby ensured, addressing several weaknesses associated with the Sobel test $[75,76]$. As students within a single group had a common instructor, the structure of the data was controlled by applying the Huber-White sandwich estimator [77].

\section{Results}

First, results of an EFA results provided empirical evidence for distinguishing between flow and GE in terms of absorption. All items loaded statistically significantly on their respective construct. CFA results further revealed a superior fit for the eight-factor measurement model compared with the competing models $\left(\chi^{2} / d f=\right.$ $1.81, \mathrm{SRMR}=.06, \mathrm{RMSEA}=.05, \mathrm{CFI}=.93, \mathrm{TLI}=.92)$. Convergent and discriminant validity were confirmed across this measurement model.

To control for CMV, procedural remedies were implemented in the ex ante research design stage. Respondents' anonymity was protected, respondents' evaluation apprehension was reduced, the order of predictor and criterion variables was counterbalanced, and the item wording was improved [73]. As an ex post statistical remedy, Harman's single-factor test using EFA and CFA was conducted, and the effects of a single unmeasured latent method factor were controlled for $[73,74]$. The EFA results showed that no single factor emerged, and one general factor failed to explain most of the variance. Next, the CFA results indicated that CMV was minimized [73]. CMV was further examined using the single unmeasured latent factor method $[71,78]$. The latent factor method gave no cause for concern regarding CMV [79], indicating that CMV was not a significant issue in the present study.

Results of multiple hierarchical regression analyses regarding $\mathrm{H} 1$ confirmed a positive relationship between perceived instructional support and students' GE. The relationship between perceived instructional support and GE in terms of enjoyment was the strongest $(B=.35, p<.001)$, compared with the dimensions of absorption $(\beta=.19$, $p<.01)$, creative thinking $(\beta=.24, p<.001)$, absence of negative affect $(\beta=.22, p<.001)$, and dominance $(\beta=.17$, $p<.001)$. Thus, H1 was supported.

The results of mediation analyses for $\mathrm{H} 2$ showed that group engagement had a partially mediating effect on the relationship between perceived instructional support and GE in terms of enjoyment, creative thinking, and absence of negative affect (see Table 2). However, group engagement did not statistically significantly mediate the relationship between perceived instructional support and GE in terms of absorption and dominance (see Table 2). Consequently, $\mathrm{H} 2$ was somewhat supported.

In line with the expectations regarding $\mathrm{H} 3$, the mediating effect of flow on the relationship between perceived instructional support and GE was statistically significant for all dimensions of GE. Flow had a partially mediating effect on the relationship between perceived instructional support and GE in terms of enjoyment and absorption, as well as a total mediation effect in terms of the other dimensions of GE (see Table 2). Thus, H3 was supported.

Finally, H4 was supported, indicating that students' group engagement and flow sequentially double-mediated the positive relationship between perceived instructional support and students' GE in terms of all its dimensions. Our double-mediation model, explaining $17 \%$ to $48 \%$ of the variance, showed statistically significant yet weak indirect effects, ranging from .02 to .04 (see Table 2).

\section{Discussion and implications}

This study extended previous research by providing valuable insights into students' GE in higher education. By addressing a major research gap in the context of DGBL, a double-mediation model was developed that investigates the factors that encourage GE among students and provides empirical evidence of a team-based business simulation game.

First, based on the empirical results, the current study confirmed that flow is a predisposing factor regarding students' GE, thus extending prior research. In line with the theory of experience $[13,14]$ and previous research [37, $80,81]$, perceived instructional support increased students' GE in terms of all its dimensions. Perceived instructional support successfully encouraged students' positive emotional experiences, such as enjoyment; further, it did not encourage negative emotions [38, 80]. Moreover, in line with Proserpio and Magni [39], perceived instructional support prevented students from becoming distracted, increasing their absorption.

Thus, instructors were able to cognitively engage their students [2]. Perceived instructional support fostered creative thinking, such as students' imaginative or explorative capacities. In line with existing research, perceived instructional support also increased students' feeling of dominance, implying that they were in control while playing the game [2, 6, 32, 33].

Regarding the mediation hypotheses (H2-H3), the analyses revealed that group engagement partially mediated the relationship between perceived instructional support and GE in terms of enjoyment, creative thinking, and absence of negative affect. Thus, in line with the theory of experience and previous research, perceived instructional support promoted group engagement, thereby increasing students' positive emotions related to the game in terms of 
Table 2: Tests for Mediation Hypotheses Using Bootstrapping

\begin{tabular}{|c|c|c|c|c|c|c|c|c|c|c|c|c|c|c|}
\hline \multirow[t]{2}{*}{ Dependent variables } & \multicolumn{3}{|c|}{ GE Enjoyment } & \multicolumn{2}{|c|}{ GE Absorption } & \multicolumn{3}{|c|}{ GE Creative thinking } & \multicolumn{3}{|c|}{$\begin{array}{l}\text { GE Absence of } \\
\text { negative affect }\end{array}$} & \multicolumn{3}{|c|}{ GE Dominance } \\
\hline & $\begin{array}{l}\text { Effect } \\
\text { size }\end{array}$ & $S E$ & $\begin{array}{l}\text { BootLLCl; } \\
\text { BootULCl }\end{array}$ & $\begin{array}{l}\text { Effect } \\
\text { size }\end{array}$ & SE $\begin{array}{l}\text { BootLLCl; } \\
\text { BootULCl }\end{array}$ & $\begin{array}{l}\text { Effect } \\
\text { size }\end{array}$ & $S E$ & $\begin{array}{l}\text { BootLLCl; } \\
\text { BootULCl }\end{array}$ & $\begin{array}{c}\text { Effect } \\
\text { size }\end{array}$ & $S E$ & $\begin{array}{l}\text { BootLLCl; } \\
\text { BootULCl }\end{array}$ & $\begin{array}{l}\text { Effect } \\
\text { size }\end{array}$ & $S E$ & $\begin{array}{l}\text { BootLLCl; } \\
\text { BootULCl }\end{array}$ \\
\hline \multicolumn{15}{|l|}{ Indirect effects } \\
\hline Group engagement & .05 & .02 & {$[.01, .09]$} & .01 & $.02[-.02, .04]$ & .05 & .02 & {$[.02, .09]$} & .09 & .03 & {$[.04, .14]$} & .01 & .01 & {$[-.02, .03]$} \\
\hline Flow & .13 & .03 & {$[.07, .20]$} & .06 & $.02[.03, .10]$ & .12 & .03 & {$[.06, .17]$} & .07 & .02 & {$[.03, .12]$} & .11 & .03 & {$[.06, .16]$} \\
\hline \multicolumn{15}{|l|}{$\begin{array}{l}\text { Double-mediating } \\
\text { effect of group }\end{array}$} \\
\hline engagement AND flow & .04 & .01 & {$[.01, .07]$} & .02 & $.01 \quad[.01, .03]$ & .03 & .01 & {$[.01, .06]$} & .02 & .01 & {$[.01, .04]$} & .03 & .01 & {$[.01, .06]$} \\
\hline$R^{2}$ & \multicolumn{3}{|c|}{.48} & \multicolumn{2}{|r|}{.17} & \multicolumn{3}{|c|}{.39} & \multicolumn{3}{|c|}{.31} & \multicolumn{3}{|c|}{.42} \\
\hline$d f 1, d f 2$ & \multicolumn{3}{|c|}{12,323} & \multicolumn{2}{|r|}{12,323} & \multicolumn{3}{|c|}{12,323} & \multicolumn{3}{|c|}{12,323} & \multicolumn{3}{|c|}{12,323} \\
\hline$F$ & \multicolumn{3}{|c|}{$33,07^{\star \star \star}$} & \multicolumn{2}{|r|}{$6.61^{\star \star *}$} & \multicolumn{3}{|c|}{$19.83^{* * *}$} & \multicolumn{3}{|c|}{$15.81^{* * *}$} & \multicolumn{3}{|c|}{$22.33^{\star \star \star}$} \\
\hline
\end{tabular}

Note. $N=336$. GE: gameful experience. SE : standard error.

${ }^{*} p<.05 .{ }^{* *} p<.01 .{ }^{* * *} p<.001$

enjoyment and absence of negative affect, as well as their creative thinking $[46,51,52]$. Concerning the relationship between perceived instructional support and GE in terms of absorption and dominance, group engagement was not a significant mediator. Although perceived instructional support enhanced group engagement, the support did not increase students' absorption or their sense of dominance. An explanation for this may be that students cannot get fully absorbed in or control the game on their own, as they must coordinate with their group members and work toward common goals [20, 29, 39]. Further, group engagement may cause interruptions, distracting students from the game [50].

Referring to the individual factor, the results confirmed prior research by finding that perceived instructional support encouraged students' flow [2, 31, 58, 82]. Instructors provided their support carefully to encourage flow [6]. Although students' flow intensity was a valuable determinant of their GE, perceived instructional support, if implemented successfully, further intensified students' flow and enhanced GE.

Last, the empirical results provided evidence for the double-mediation model regarding all dimensions of GE. Perceived instructional support increased students' group engagement and further intensified their flow. In turn, this fostered their enjoyment and positive emotions, their distraction from their actual environment, their imaginative and explorative capacities, as well as their feeling of control while playing [2].

In addition to the relevance of the double-mediation model, only the direct relationship between perceived instructional support and GE enjoyment remained statistically significant in the final model. So, while instructional support was found to be a relevant determinant of students' GE, instructional support is further crucial to promote interpersonal and individual factors in terms of group engagement and flow that subsequently encourage students' GE.

The results of the current study emphasized the relevance of considering the theory of experience when investigating team-based business simulation games in DGBL. The principles of both continuity and interaction are determining the quality of students' GE. Specifically, the current study confirmed that instructors play a key role in fostering group engagement and flow in business simulation games in order to encourage GE. Instructors of business simulation games should prevent disruptions and reduce students' distraction from the game to promote GE.

Researchers, educators, and educational policy makers should pay more attention to encouraging GE among students in order to enhance students' motivation, their learning, and the overall effectiveness of educational games. It is recommended that higher education institutions worldwide make use of DGBL.

\section{Limitations and future research}

Although this study provides new insights into students' GE, several limitations exist, and further research is needed. First, the data came from only two universities in Germany, deriving from only one business simulation game. To generalize the findings to other universities or games, the varying effects of business simulation games on GE should be investigated in various educational contexts. Second, concerning the GAMEX scale used in this study, the dimension activation was eliminated as a dimension. Although its exclusion was justified based on statistical and content-related considerations, doing so limited the scale's validity in the context of DGBL. Additional research is required to determine whether activation is dependent on the game itself, and whether games (e.g., business simulation games) in the context of DGBL cannot stimulate students' emotions, thoughts, and actions [2]. Third, as single-source data, self-reported by the respondents, were used, our study design controlled somewhat for CMV bias, and this should be addressed in future research [73, 74]. Fourth, due to the cross-sectional design of this study, it was not possible to identify causal relationships between the variables of interest. In line with Podsakoff et al. [73], further research employing longitudinal or experimental study designs is needed to verify the hypothesized relationships. 


\section{Conclusion}

This study contributes to and advances research on the use of games in DGBL by providing valuable empirical insights into GE, a precondition for the effectiveness of games. The current study extends existing research by investigating a team-based business simulation game and applicating the GAMEX scale to the context of DGBL in higher education. By doing so, a double-mediation model was used to investigate how group engagement and flow sequentially double-mediate the relationship between perceived instructional support and students' GE.

Empirical evidence of a team-based business simulation game confirmed that perceived instructional support is a valuable determinant of students' GE. Also, interpersonal, and individual factors in terms of group engagement and flow were crucial mediating factors in this relationship. Particularly, at the interpersonal level, the perceived instructional support in the business simulation game increased group engagement, thereby enhancing students' individual learning experiences (i.e., their GE in terms of enjoyment, creative thinking, and absence of negative affect). However, group engagement did not indirectly encourage students' GE in terms of absorption and dominance. At the individual level, perceived instructional support fostered students' intensity of flow, thereby encouraging GE in terms of all its dimensions. Finally, the results verified that the double-mediation effect of group engagement and flow sequentially encouraging the positive relationship between perceived instructional support and students' GE.

Based on the results of the current study, it should be noted that instructors of business simulation games must provide their support carefully in order to promote GE. Moreover, educators should ensure group engagement and avoid disruptions, aiming to promote students' motivation, their learning, and the overall effectiveness of DGBL in higher education.

\section{References}

[1] M. Sailer, and L. Homner, "The Gamification of Learning: a Meta-analysis", Educational Psychology Review, 32 (1), 2020, pp. 77-112.

[2] T. Leclercq, I. Poncin, and W. Hammedi, "Opening the black box of gameful experience: Implications for gamification process design", Journal of Retailing and Consumer Services, 52, 2020, pp. 1-27.

[3] H.E. Vidergor, "Effects of digital escape room on gameful experience, collaboration, and motivation of elementary school students", Computers \& Education, 166, 2021, p. 104156.

[4] N. Nehring, N. Baghaei, and S. Dacey, Improving students' performance through gamification: a user study: in: Proceedings of the 10th International Conference on Computer Supported Education, Funchal, 2018, pp. 213-218.
[5] M. Prensky, "Digital Natives, Digital Immigrants", On the horizon, 9 (5), 2001, pp. 1-6.

[6] P. Wouters, and H. van Oostendorp, "A meta-analytic review of the role of instructional support in game-based learning", Computers \& Education, 60 (1), 2013, pp. 412425.

[7] R.N. Landers, "Developing a Theory of Gamified Learning: Linking Serious Games and Gamification of Learning", Simulation \& Gaming, 45 (6), 2014, pp. 752-768.

[8] J. Pando-Garcia, I. Periañez-Cañadillas, and J. Charterina, "Business simulation games with and without supervision”, Journal of Business Research, 69 (5), 2016, pp. 1731-1736.

[9] I. Buil, S. Catalán, and E. Martínez, "Encouraging intrinsic motivation in management training", The International Journal of Management Education, 17 (2), 2019, pp. 162171.

[10] J. Högberg, J. Hamari, and E. Wästlund, “Gameful Experience Questionnaire (GAMEFULQUEST): an instrument for measuring the perceived gamefulness of system use", User Modeling and User-Adapted Interaction, 29 (3), 2019, pp. 619-660.

[11] K. Huotari, and J. Hamari, "A definition for gamification: anchoring gamification in the service marketing literature", Electronic Markets, 27 (1), 2017, pp. 21-31.

[12] R.N. Landers, G.F. Tondello, D.L. Kappen, A.B. Collmus, E.D. Mekler, and L.E. Nacke, "Defining Gameful Experience as a Psychological State Caused by Gameplay", International Journal of Human-Computer Studies, 127, 2019, pp. 81-94.

[13] J. Dewey, "Experience and Education", The Educational Forum, 50 (3), 1986, pp. 241-252.

[14] J. Dewey, Experience and Education: Collier Books, New York, 1938.

[15] T. Anastasiadis, G. Lampropoulos, and K. Siakas, "Digital Game-based Learning and Serious Games in Education", International Journal of Advances in Scientific Research and Engineering, 4 (12), 2018, pp. 139-144.

[16] D.R. Michael, and S. Chen, Serious Games: Course Technology, Mason, 2005.

[17] Deterding, S., Dixon, D., Khaled, R., \& Nacke, L., From Game Design Elements to Gamefulness: Defining "Gamification": in: Proceedings of the 15th international academic MindTrek conference, Tampere, New York, 2011, 9-15.

[18] R. Eppmann, M. Bekk, and K. Klein, "Gameful experience in gamification: Construction and validation of a gameful experience scale [GAMEX]", Journal of Interactive Marketing, 43, 2018, pp. 98-115.

[19] A. García-Viola, J.M. Garrido-Molina, V.V. MárquezHernández, G. Granados-Gámez, G. Aguilera-Manrique, and L. Gutiérrez-Puertas, "The Influence of Gamification on Decision Making in Nursing Students", Journal of Nursing Education, 58 (12), 2019, pp. 718-722.

[20] A.B. Hernández-Lara, A. Perera-Lluna, and E. SerradellLópez, "Applying learning analytics to students' interaction in business simulation games.", Computers in Human Behavior, 92, 2019, pp. 600-612.

[21] J.C. Turner, P.K. Thorpe, and D.K. Meyer, "Students' reports of motivation and negative affect: A theoretical and 
empirical analysis", Journal of Educational Psychology, 90 (4), 1998, pp. 758-771.

[22] V.V. Márquez-Hernández, J.M. Garrido-Molina, L. Gutiérrez-Puertas, A. García-Viola, G. Aguilera-Manrique, and G. Granados-Gámez, "How to measure gamification experiences in nursing? Adaptation and validation of the Gameful Experience Scale GAMEX”, Nurse education today, 81, 2019, pp. 34-38.

[23] M. Schmidt, "Learning from teaching experience: Dewey's theory and preservice teachers' learning", Journal of research in music education, 58 (2), 2010, pp. 131146.

[24] E. Houmøller, and E. Marchetti, Playing Facilitators: Care and Tough Love in Games Based Learning Contexts: in: European Conference on Games Based Learning, Steinkjer, Sonning Common, 2015, pp. 242-249.

[25] V. Marc, "Rethinking the meaning of study abroad programs: The learning experiences of two female Gambian students in Taiwan", Journal of Global Education and Research, 3 (1), 2019, pp. 37-57.

[26] A.I. Abdul Jabbar, and P. Felicia, "Gameplay engagement and learning in game-based learning: A systematic review", Review of Educational Research, 85 (4), 2015, pp. 740-779.

[27] R. Garris, R. Ahlers, and J.E. Driskell, "Games, motivation, and learning: A research and practice model", Simulation \& Gaming, 33 (4), 2002, pp. 441-467.

[28] H. Leemkuil, and T.O. de Jong, "Adaptive advice in learning with a computer-based knowledge management simulation game", Academy of Management Learning \& Education, 11 (4), 2012, pp. 653-665.

[29] C. Uz Bilgin, and A. Gul, "Investigating the Effectiveness of Gamification on Group Cohesion, Attitude, and Academic Achievement in Collaborative Learning Environments", TechTrends, 64 (1), 2020, pp. 124-136.

[30] W. Admiraal, J. Huizenga, S. Akkerman, and G. ten Dam, "The concept of flow in collaborative game-based learning", Computers in Human Behavior, 27 (3), 2011, pp. 1185-1194.

[31] K. Kiili, "Digital game-based learning: Towards an experiential gaming model", The Internet and higher education, 8 (1), 2005, pp. 13-24.

[32] J. ter Vrugte, and T. de Jong, How to Adapt Games for Learning: The Potential Role of Instructional Support: in: S. de Wannemacker, S. Vandercruysse, G. Clarebout (Eds.), Serious Games: The Challenge, Springer, Berlin, 2012, pp. 1-5.

[33] J. ter Vrugte, T. de Jong, P. Wouters, S. Vandercruysse, J. Elen, and H. van Oostendorp, "When a game supports prevocational math education but integrated reflection does not", Journal of Computer Assisted Learning, 31 (5), 2015, pp. 462-480.

[34] S. Kelly, and Y. Zhang, "Teacher Support and Engagement in Math and Science: Evidence from the High School Longitudinal Study", The High School Journal, 99 (2), 2016, pp. 141-165.

[35] C.I. Johnson, and R.E. Mayer, "Applying the self-explanation principle to multimedia learning in a computerbased game-like environment", Computers in Human Behavior, 26 (6), 2010, pp. 1246-1252.
[36] H. Tüzün, "Blending video games with learning: Issues and challenges with classroom implementations in the Turkish context", British Journal of Educational Technology, 38 (3), 2007, pp. 465-477.

[37] P. Norton, and D. Hathaway, "Exploring two teacher education online learning designs: A classroom of one or many?", Journal of Research on Technology in Education, 40 (4), 2008, pp. 475-495.

[38] M.-H.M. Chen, S.-T. Tsai, and C.-C. Chang, "Effects of game-based instruction on the results of primary school children taking a natural science course", Education Sciences, 9 (2), 2019, pp. 79-94.

[39] L. Proserpio, and M. Magni, "Teaching without the teacher? Building a learning environment through computer simulations", International Journal of Information Management, 32 (2), 2012, pp. 99-105.

[40] W.-H. Wu, H.-C. Hsiao, P.-L. Wu, C.-H. Lin, and S.-H. Huang, "Investigating the learning-theory foundations of game-based learning: a meta-analysis", Journal of Computer Assisted Learning, 28 (3), 2012, pp. 265-279.

[41] T. Seechaliao, "Instructional strategies to support creativity and innovation in education", Journal of education and learning, 6 (4), 2017, pp. 201-208.

[42] J. López-Belmonte, A. Segura-Robles, A. FuentesCabrera, and M.E. Parra-González, "Evaluating activation and absence of negative effect: Gamification and Escape Rooms for learning", International Journal of Environmental Research and Public Health, 17 (7), 2020, pp. 2224-2236.

[43] A.E. Black, and E.L. Deci, "The Effects of Instructors' Autonomy Support and Students' Autonomous Motivation on Learning Organic Chemistry", Science Education, 84 (6), 2000, pp. 740-756.

[44] M.D. Kickmeier-Rust, and D. Albert, "Micro-adaptivity: Protecting immersion in didactically adaptive digital educational games", Journal of Computer Assisted Learning, 26 (2), 2010, pp. 95-105.

[45] H. Leemkuil, Is it all in the game? Learner support in an educational knowledge management simulation game: University of Twente, Enschede, 2006.

[46] E.A. Gomez, D. Wu, and K. Passerini, "Computer-supported team-based learning: The impact of motivation, enjoyment and team contributions on learning outcomes", Computers \& Education, 55 (1), 2010, pp. 378-390.

[47] K.R. MacKenzie, and W.J. Livesley, Stages and roles: the group and the individual: in: L.R. Wolberg, M. Aronson (Eds.), Group and Family Therapy, Brunner/Mazel, New York, 1983, pp. 78-88.

[48] M. Popescu, S. Arnab, R. Berta, J. Earp, S. de Freitas, M. Romero, I. Stanescu, and M. Usart, Serious Games in Formal Education: Discussing Some Critical Aspects: in: Proceedings 5th European Conference on Game-Based Learning, Athens, Sonning Common, 2011.

[49] H. Wang, H.-T. Yang, and C.-T. Sun, "Thinking style and team competition game performance and enjoyment", IEEE Transactions on Computational Intelligence and AI in Games, 7 (3), 2015, pp. 243-254.

[50] Leavitt, A., Keegan, B. C., Clark, J., Ping to win? nonverbal communication and team performance in competitive online multiplayer games: San Jose, 2016, pp. 43374350 . 
[51] L.L. Gilson, and C.E. Shalley, "A Little Creativity Goes a Long Way: An Examination of Teams' Engagement in Creative Processes", Journal of Management, 30 (4), 2004, pp. 453-470.

[52] S. Chanda-Gool, and C. Mamas, "Coming from somewhere else'-group engagement between students and academics", Journal of Learning Development in Higher Education, 12, 2017, pp. 1-17.

[53] C. Thompson, S. Mohamed, W.Y.G. Louie, J.C. He, J. Li, and G. Nejat, The robot Tangy facilitating Trivia games: A team-based user-study with long-term care residents: Ottawa, 2017, pp. 173-178.

[54] M. Csikszentmihalyi, "Play and Intrinsic Rewards", Journal of Humanistic Psychology, 15 (3), 1975, pp. 41-63.

[55] D.J. Shernoff, M. Csikszentmihalyi, B. Schneider, and E.S. Shernoff, Student Engagement in High School Classrooms from the Perspective of Flow Theory: in: M. Csikszentmihalyi (Ed.), Applications of Flow in Human Development and Education, Springer, Claremont, 2014, pp. 475-494.

[56] M. Csikszentmihalyi, Flow: The Psychology of Optimal Experience: Harper Perennial, New York, 1990.

[57] J.H. Brockmyer, C.M. Fox, K.A. Curtiss, E. McBroom, K.M. Burkhart, and J.N. Pidruzny, "The development of the Game Engagement Questionnaire: A measure of engagement in video game-playing", Journal of Experimental Social Psychology, 45 (4), 2009, pp. 624-634.

[58] D.L. Hoffman, and T.P. Novak, "Marketing in hypermedia computer-mediated environments: Conceptual foundations", Journal of marketing, 60 (3), 1996, pp. 50-68.

[59] N. Shin, "Online learner's 'flow'experience: an empirical study”, British Journal of Educational Technology, 37 (5), 2006, pp. 705-720.

[60] T. Ljubin-Golub, M. Rijavec, and D. Olčar, "Student flow and burnout: The role of teacher autonomy support and student autonomous motivation", Psychological Studies, 65 (2), 2020, pp. 145-156.

[61] J. Hamari, D.J. Shernoff, E. Rowe, B. Coller, J. AsbellClarke, and T. Edwards, "Challenging games help students learn: An empirical study on engagement, flow and immersion in game-based learning", Computers in Human Behavior, 54, 2016, pp. 170-179.

[62] J.E. Johnson, "Beware of Storming: Research Implications for Interpreting Group Climate Questionnaire Scores Over Time", International Journal of Group Psychotherapy, 63 (3), 2013, pp. 433-446.

[63] Y. Inal, and K. Cagiltay, "Flow experiences of children in an interactive social game environment", British Journal of Educational Technology, 38 (3), 2007, pp. 455-464.

[64] P. Sweetser, and P. Wyeth, "GameFlow: a model for evaluating player enjoyment in games", Computers in Entertainment, 3 (3), 2005, pp. 1-24.

[65] C. Fornell, and D.F. Larcker, "Evaluating structural equation models with unobservable variables and measurement error", Journal of Marketing Research, 18 (1), 1981, pp. $39-50$.

[66] L. Rhoades, R. Eisenberger, and S. Armeli, "Affective commitment to the organization", Journal of Applied Psychology, 86 (5), 2001, pp. 825-836.

[67] K.R. MacKenzie, The clinical application of a group climate measure: in: R.R. Dies, K.R. MacKenzie (Eds.),
Advances in group psychotherapy: Integrating research and practice, first ed., International Universities Press, New York, 1983, pp. 159-170.

[68] V. Tschuschke, H. Hess, and K.R. MacKenzie, "Der Gruppenklima-Fragebogen (GCQ-S)-Methodik und Anwendung eines Meßinstruments zum Gruppenerleben", Gruppenpsychotherapie und Gruppendynamik, 26, 1991, pp. 340-359.

[69] F. Rheinberg, R. Vollmeyer, and S. Engeser, Die Erfassung des Flow-Erlebens: in: J. Stiensmeier-Pelster, F. Rheinberg (Eds.), Diagnostik von Motivation und Selbstkonzept, Hogrefe Verlag, Göttingen, 2003, pp. 261-279.

[70] A.F. Hayes, Introduction to mediation, moderation, and conditional process analysis a regression based approach: Guilford Press, New York, 2013.

[71] X. Hu, and Z. Jiang, "Employee-oriented HRM and voice behavior: a moderated mediation model of moral identity and trust in management", The International Journal of Human Resource Management, 29 (5), 2018, pp. 746771.

[72] Z. Zhang, M. Wang, and J. Shi, "Leader-Follower Congruence in Proactive Personality and Work Outcomes", Academy of Management Journal, 55 (1), 2012, pp. 111130.

[73] P.M. Podsakoff, S.B. MacKenzie, J.-Y. Lee, and N.P. Podsakoff, "Common method biases in behavioral research", Journal of Applied Psychology, 88 (5), 2003, pp. 879-903.

[74] S.-J. Chang, A. van Witteloostuijn, and L. Eden, "From the editors: Common method variance in international business research", Journal of International Business Studies, 41 (2), 2010, pp. 178-184.

[75] K.J. Preacher, and A.F. Hayes, "Asymptotic and resampling strategies for assessing and comparing indirect effects in multiple mediator models", Behavior research methods, 40 (3), 2008, pp. 879-891.

[76] X. Zhao, J.G. Lynch Jr, and Q. Chen, "Reconsidering Baron and Kenny: Myths and truths about mediation analysis", Journal of consumer research, 37 (2), 2010, pp. 197-206.

[77] W.S. Crawford, E. Lamarre, K.M. Kacmar, and K.J. Harris, "Organizational Politics and Deviance: Exploring the Role of Political Skill”, Human Performance, 32 (2), 2019 , pp. 92-106.

[78] F. Castanheira, "Perceived social impact, social worth, and job performance: Mediation by motivation", Journal of Organizational Behavior, 37 (6), 2016, pp. 789-803.

[79] R.P. Bagozzi, and Y. Yi, "Assessing method variance in multitrait-multimethod matrices", Journal of Applied Psychology, 75 (5), 1990, pp. 547-560.

[80] A. Heirdsfield, S. Walker, M. Tambyah, and D. Beutel, "Blackboard as an online learning environment: What do teacher education students and staff think?", Australian Journal of Teacher Education, 36 (7), 2011, pp. 1-16.

[81] E.J. Shinsky, and H.A. Stevens, "Teaching in educational leadership using web 2.0 applications", Journal of Research on Leadership Education, 6 (5), 2011, pp. 195-215.

[82] H. Chen, R.T. Wigand, and M.S. Nilan, "Optimal experience of Web activities", Computers in Human Behavior, 15 (5), 1999, pp. 585-608. 